\title{
Anabena sp. Mediated Modulation of Arsenic Accumulation Enhances Tolerance Responses in Oryza sativa L.
}

\author{
Ruma Ranjan ${ }^{1,2}$, S.N. Pandey ${ }^{2}$, S.S. Mallick ${ }^{1^{*}}$ \\ ${ }^{I}$ CSIR-National Botanical Research Institute, Lucknow, India \\ ${ }^{2}$ Department of Botany, University of Lucknow, Lucknow, India \\ Address for Correspondance: S.S. Mallick, shekharm@nbri.res.in
}

Keywords Arsenic; Toxicity; Cyanobacteria; Biotransformation; Methylation.

\begin{abstract}
Arsenic (As) is a non threshold carcinogen, present in ground water and agricultural fields of Indian subcontinent. Arsenic affects human health through consuming As contaminated food. Minimization of As uptake through cyanobacteria could be a feasible and environmental friendly techniques. Arsenic biotransformation by cyanobacteria may play a critical role in the fate and toxicity iAs (inorganic As) to relatively less toxic methylated oAs (organic As). Presented results showed that As tolerant Anabaena sp. not only grow at high concentration $1000 \mu \mathrm{M}$ of arsenate $[\mathrm{As}(\mathrm{V})]$, but also have the ability to accumulate the high (3556.1 $\left.\mu \mathrm{g} \mathrm{g}^{-1} \quad \mathrm{DW}\right)$ concentration of $\mathrm{As}(\mathrm{V})$ (500 $\mu \mathrm{M})$. Experiment was carried out (i) to indentify the tolerant Anabaena sp. towards Arsenic $[\mathrm{As}(\mathrm{V})$ and $\mathrm{As}(\mathrm{III})]$ and (ii) quantify the reduction of As toxicity in rice cv. saryoo-52 seedlings co-cultured with 10\% Anabaena $s p$. which was treated with $\mathrm{As}(\mathrm{V})$ and $\mathrm{As}(\mathrm{III})(30-60 \mu \mathrm{M})$, under hydroponic growth conditions using Hewitt media. The As uptake was found to reduce in rice when grown with Anabaena sp. by $48.79 \%$ and $33.25 \%$ against $60 \mu \mathrm{m}$ As(III) and $60 \mu \mathrm{m} \mathrm{As}(\mathrm{V})$, respectively. The rice seedlings co-cultured with Anabaena sp. also showed significant decreased in the level of TBARS and $\mathrm{H}_{2} \mathrm{O}_{2}$ under As stress. Similarly, activity of antioxidant enzymes such as SOD, GR, CAT and GPX were also decreased with As and co-cultured Anabaena sp.. The results provide initial evidence that Anabaena sp. inhibits As accumulation and modulates tolerance responses towards As. (C) 2016 iGlobal Research and Publishing Foundation. All rights reserved.
\end{abstract}

Conference Proceedings: International Conference on Advances in Plant and Microbial Biotechnology (PMB2017); JIIT, Noida: February 02-04, 2017

Indo Global Journal of Pharmaceutical Sciences( ISSN 22491023 ; CODEN- IGJPAI; NLM ID: 101610675) indexed and abstracted in EMBASE(Elsevier), SCIRUS(Elsevier),CABI, CAB Abstracts, Chemical Abstract Services(CAS), American Chemical Society(ACS), Index Copernicus, EBSCO, DOAJ, Google Scholar and many more. For further details, visit http://iglobaljournal.com 